\title{
Generation of an Annual Typical Meteorological Wind Speed for Armidale NSW,Australia
}

\author{
Yasser Maklad ${ }^{1}$ \\ ${ }^{1}$ (University of New England, Armidale NSW 2351 NSW Australia-School of Environmental \& Rural Science - \\ email:ymaklad@myune.edu.au)
}

\begin{abstract}
The most common data for describing the local wind climate is through what is called Typical Meteorological Year data (TMY). Typical wind speed data is very important for the calculations of many wind applications. In this study, Typical Wind Speed year for Armidale town in New South Wales in Australia are generated from the daily and monthly wind speed data measured at ten meter height from ground level and collected for 20 years during the period 1994 to 2013, utilising the Finkelstein-Schafer statistical method. The study outcome is expected to show how wind speed is potential in Armidale NSW and would be a real help for wind energy generation systems' designers in this region for all building applications varying between residential, educational, administrative and commercial for sizing and maximising efficiency of such systems by using the tabular TYR outcome for the each day of the year.
\end{abstract}

Keywords:- Armidale NSW, test meteorological year, test reference year, wind speed

\section{INTRODUCTION}

The most common data for describing the local wind climate is through what is called Typical Meteorological Year data (TMY). To determine TMY data, various meteorological measurements are made at hourly intervals over a number of years to build up a picture of the local climate. A simple average of the yearly data underestimates the amount of variability, so the month that is most representative of the location is selected. For each month, the average wind speed over the whole measurement period is determined, together with the average wind speed in each month during the measurement period. The data for the month that has the average wind speed most closely equal to the monthly average over the whole measurement period is then chosen as the TMY data for that month. This process is then repeated for each month in the year. The months are added together to give a full year of hourly samples. There is no strict standard for TMY data so the user must adjust the data to suit the application. Considerable care must be taken with sample periods. Wind speed data is a crucial parameter for the prediction of long-term performance of wind energy generation systems. As well, it is a key input in modelling and designing of wind energy applications. Thus, a need for a reliable source of wind speed data has to be readily available for particular settlement locations.

The need for a one-year representative daily meteorological data led to the development of methodologies known as the Typical Meteorological Year (TMY), alternatively called Test Reference Year (TRY) [1]. TMY or TRY is a representative data that consists of the month selected from the individual years and concatenated to form a complete year. However, A TMY is not necessarily a good indicator of conditions over the next year or even the next five years. Rather, TMY represents conditions judged to be typical over a long period of time [2]. Typical weather year data sets can be generated for several climatic variables such as temperature, humidity, wind speed, etc. or only for wind speed. Various trials have been made to generate such weather databases for different areas around the world [1, 3, 4, 5, 6, 7, 8, 9, 10, 13 \& 14].

Thus, The main aim of this study is to generate representative TYM of wind speed data for Armidale NSW, Australia

\section{DATA AND LOCATION}

The daily mean wind speed recorded during the period 1994-2010 are utilized to generate the typical wind speed data. In Australia, meteorological observations are recorded by the Australian Bureau of Meteorology (BOM) weather stations are widely spreader in lots of cities and towns around Australia. In this study, the global wind speed data recorded by Armidale Airport Weather Automatic Station and published on the BOM's website where it was collected. The missing and invalid measurements account for $0.001 \%$ of the whole database of mean wind speed; those were replaced with the values of preceding or subsequent days by interpolation. During the calculations process, any year found with more than ten days in any month observations not available was excluded. "Table 1" provides geographical information for Armidale town and the periods of the relevant mean wind speed data. 
Table 1 Geographical and mean wind speed database information of Armidale NS, Australia Longitude ( $†$ E) Latitude $(† S) \quad$ Elevation $(\mathrm{m}) \quad$ Mean Daily Wind Speed

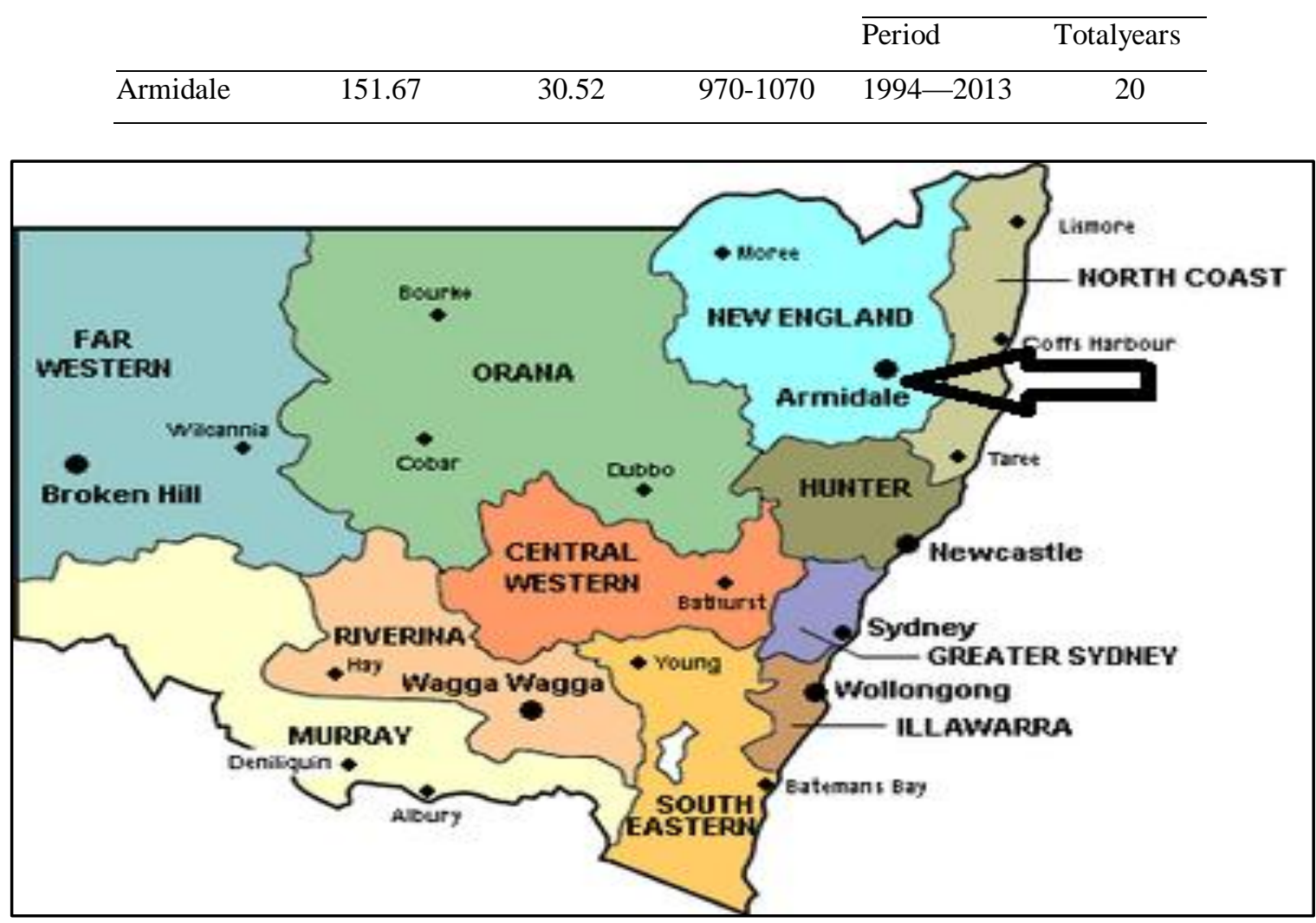

Figure1 Armidale NSW, Australia location

\section{METHODOLOGY}

Finkelstein-Schafer (FS) statistics [11] is a nonparametric statistical method, known as common methodology for generating typical weather data $[1,2,3,4,5,8,9,10 \& 12]$. In this study, FS methodology is used for generating the typical wind speed year. According to FS statistics [11], if a number, $n$, of observations of a variable $\mathrm{X}$ are available and have been sorted into an increasing order $\mathrm{X} 1, \mathrm{X} 2, \ldots, \mathrm{Xn}$, the cumulative frequency distribution function $(\mathrm{CDF})$ of this variable is given by a function $\operatorname{Sn}(\mathrm{X})$, which is defined in equation (1).

$$
S_{n}(X)=\left\{\begin{array}{ccc}
0 & \text { For } X<X_{1} \\
\frac{(K-0.5)}{n} & \text { For } X_{k}<X<X_{K+1}(1) \\
1 & \text { For } & X>X_{n}
\end{array}\right.
$$

where $\mathrm{k}$ is rank order number. The FS by which comparison between the long-term CDF of each month and the $\mathrm{CDF}$ for each individual year of the month was done is given in equation (2).

$$
F S=(1 / N) \sum_{i=1}^{n} \delta_{i}(2)
$$

where $\mathrm{i}$ is the absolute difference between the long-term CDF of the month and one-year CDF for the same month at $\mathrm{Xi}(\mathrm{i}=1,2, \mathrm{n}), \mathrm{n}$ being the number of daily readings of the month. di and $\mathrm{F}(\mathrm{Xi})$ are expressed with the following equations $(3 \& 4)$.

$$
\delta_{i}=\max \left[\left|F\left(X_{I}\right)-\frac{(i-1)}{n}\right|,\left|F\left(X_{i}\right)-\frac{i}{n}\right|\right](3)
$$




$$
F\left(X_{i)}=1-\exp \left(-X_{i} / \bar{X}\right)(4)\right.
$$

where $\mathrm{Xi}$ is an order sample value in a set of $\mathrm{n}$ observations sorted in an increasing order and $\mathrm{X}$ is the sample average.

Finally, the representative year for each month of the data set was determined on the basis that the representative year is that of the smallest value of FS as in equation (5).

$$
T R Y=\operatorname{MIN}(F S)=\operatorname{MIN}\left(\delta_{i}\right)(5
$$

\section{GENERATION OF TYPICAL WIND SPEED YEAR}

Applying the above methodology for all the months in the database, the Test Reference Year for daily wind speed data was formed for Armidale.

The test reference years with minimum FS for monthly mean global wind speed for Armidale are given in "Table 2". Which shows that, although the big picture that Armidale has a high potential of wind energy, still there are considerable differences of potentiality in through the months due to the fact that Armidale's winter season (June, July and August) is relatively cloudy. "Table 2", the minimum and maximum values of monthly mean of the daily global wind speed (ITRY) at 10 meter height from ground level in Armidale, the minimum is $10.41 \mathrm{MJ} / \mathrm{m} 2$ day in June and the maximum is $25.88 \mathrm{MJ} / \mathrm{m} 2$ day in December.

Table2TestReferenceYearswithminimum (min)FSandmonthlymeanofthewind speed(ITRY) for Armidale NSW, Australia

\begin{tabular}{|c|c|c|}
\hline Month & Year & ITRY (m/s day) \\
\hline January & 2000 & 5.44 \\
\hline February & 1996 & 5.27 \\
\hline March & 2008 & 5.35 \\
\hline April & 1998 & 4.84 \\
\hline May & 2008 & 4.89 \\
\hline June & 1995 & 5.36 \\
\hline July & 1996 & 5.47 \\
\hline August & 2007 & 6.27 \\
\hline September & 2001 & 5.51 \\
\hline October & 2008 & 5.37 \\
\hline November & 1996 & 5.52 \\
\hline December & 1997 & 5.36 \\
\hline
\end{tabular}

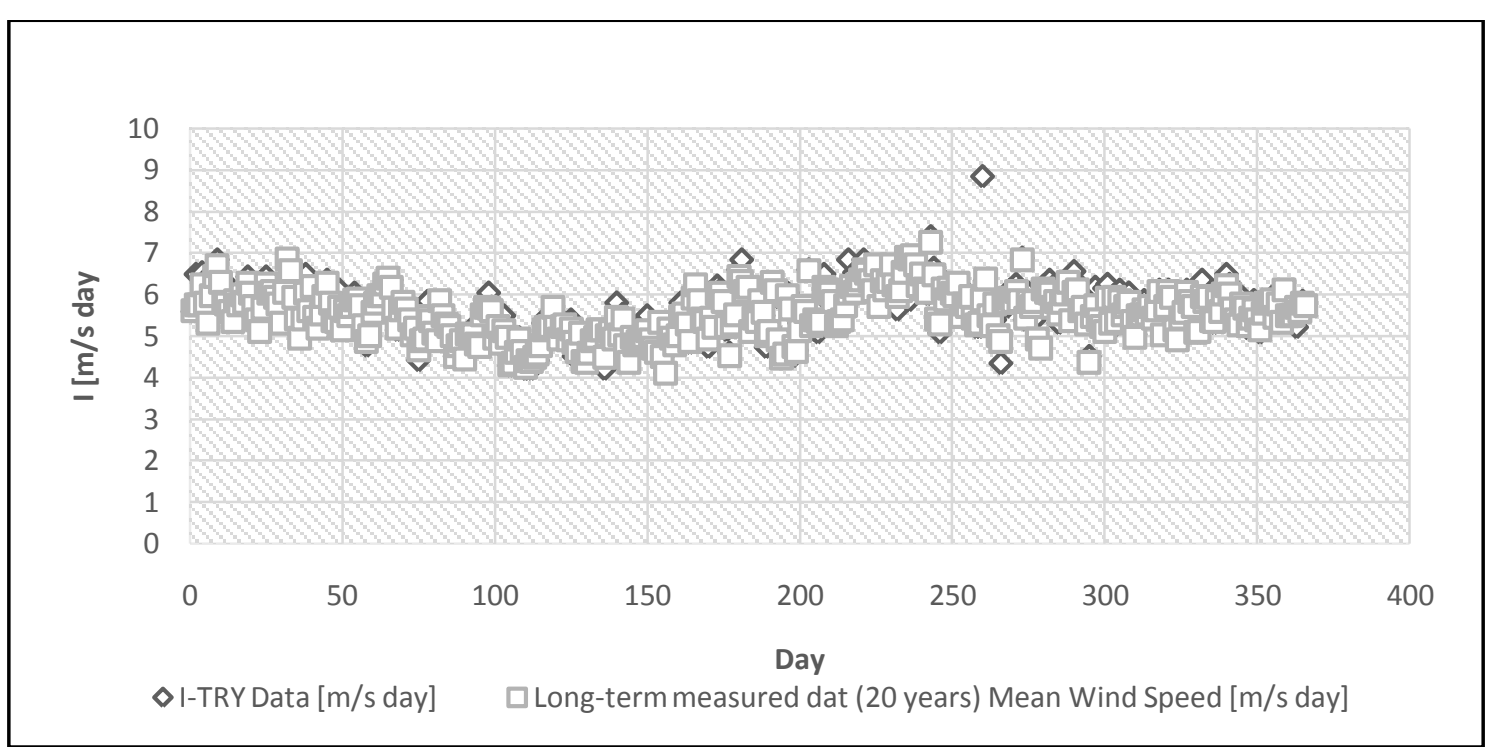

Figure2Variation ofdaily mean wind speed forArmidale NSW, Australia 
Generation of an Annual Typical Meteorological Wind Speed for Armidale NSWAustralia

Table3Daily wind speed valuesobtainedfromTestReferenceYear data for Armidale NSW, Australia

\begin{tabular}{|c|c|c|c|c|c|c|c|c|c|c|c|c|}
\hline Day & Jan & $\mathrm{Feb}$ & Mar & Apr & May & Jun & Jul & Aug & Sep & Oct & Nov & Dec \\
\hline 1 & 5.59 & 6.29 & 5.94 & 5 & 5.14 & 4.59 & 6.04 & 5.63 & 5.31 & 6.04 & 5.63 & 5.31 \\
\hline 2 & 6.49 & 6.74 & 5.86 & 5.21 & 5.31 & 5.24 & 5.31 & 5.86 & 5.08 & 5.7 & 5.86 & 5.73 \\
\hline 3 & 5.59 & 5.94 & 5.86 & 4.73 & 4.86 & 4.51 & 5.21 & 6.84 & 6.35 & 5.39 & 6.04 & 5.7 \\
\hline 4 & 6.53 & 5.45 & 6.11 & 4.76 & 5.39 & 4.1 & 5.7 & 6.11 & 5.8 & 4.96 & 5.31 & 6.04 \\
\hline 5 & 5.86 & 5.04 & 6.33 & 5.63 & 4.51 & 5.08 & 5.7 & 6.53 & 6.21 & 4.83 & 5.04 & 6.49 \\
\hline 6 & 5.9 & 5.41 & 6.35 & 5.73 & 4.96 & 5.04 & 5.49 & 6.25 & 6.25 & 6.21 & 5.49 & 6.25 \\
\hline 7 & 6.49 & 6.49 & 5.7 & 6.04 & 5.14 & 4.86 & 4.73 & 6.53 & 5.7 & 5.86 & 5.49 & 5.94 \\
\hline 8 & 6.56 & 5.63 & 5.14 & 5.7 & 4.41 & 5.39 & 5.21 & 6.84 & 6.11 & 6.35 & 5.86 & 5.41 \\
\hline 9 & 6.84 & 6.11 & 5.73 & 4.83 & 4.41 & 5.8 & 6.18 & 6.11 & 6.18 & 6.18 & 5.59 & 5.24 \\
\hline 10 & 6.11 & 5.49 & 5.63 & 5.18 & 4.73 & 5.49 & 5.94 & 6.18 & 5.49 & 5.55 & 5.63 & 5.94 \\
\hline 11 & 6.33 & 5.21 & 5.7 & 4.76 & 4.83 & 5.31 & 5.94 & 6.11 & 6.01 & 5.31 & 5.49 & 5.55 \\
\hline 12 & 5.94 & 5.7 & 5.55 & 5.49 & 4.86 & 4.83 & 4.51 & 6.6 & 5.55 & 5.55 & 5.63 & 5.18 \\
\hline 13 & 5.63 & 6.01 & 5.39 & 4.93 & 5.08 & 5.35 & 4.65 & 5.8 & 5.73 & 5.8 & 6.11 & 5.55 \\
\hline 14 & 5.63 & 6.35 & 5.08 & 4.28 & 5.14 & 6.21 & 6.04 & 6.49 & 5.21 & 6.25 & 5.21 & 5.86 \\
\hline 15 & 5.94 & 6.04 & 4.41 & 4.34 & 4.2 & 5.66 & 5.7 & 6.04 & 5.21 & 5.39 & 5.8 & 5.49 \\
\hline 16 & 5.94 & 5.39 & 4.9 & 4.65 & 5.08 & 5.21 & 4.51 & 6.53 & 8.85 & 6.56 & 6.11 & 5.08 \\
\hline 17 & 5.94 & 5.49 & 5.14 & 4.96 & 5.18 & 5.24 & 4.65 & 6.18 & 6.35 & 6.29 & 5.94 & 5.18 \\
\hline 18 & 5.94 & 6.11 & 5.84 & 4.65 & 4.86 & 4.73 & 5.31 & 6.66 & 5.31 & 5.63 & 5.49 & 5.8 \\
\hline 19 & 6.43 & 5.53 & 5.35 & 4.2 & 5.8 & 5.55 & 5.7 & 5.63 & 5.28 & 5.7 & 4.96 & 5.63 \\
\hline 20 & 6.11 & 5.7 & 5.21 & 4.34 & 5.14 & 5.18 & 5.39 & 6.11 & 5.39 & 5.39 & 5.31 & 5.94 \\
\hline 21 & 5.94 & 5.55 & 4.9 & 4.2 & 5.53 & 6.21 & 6.6 & 6.35 & 5.08 & 4.51 & 5.55 & 5.39 \\
\hline 22 & 5.45 & 5.8 & 5.39 & 4.41 & 4.93 & 6.11 & 5.14 & 6.84 & 4.34 & 5.63 & 6.11 & 5.45 \\
\hline 23 & 5.24 & 6.04 & 5.35 & 4.41 & 4.51 & 5.9 & 5.39 & 5.86 & 5.8 & 6.18 & 5.94 & 5.55 \\
\hline 24 & 6.25 & 5.94 & 5.21 & 4.83 & 4.65 & 5.14 & 5.08 & 6.6 & 5.7 & 5.39 & 5.31 & 5.86 \\
\hline 25 & 6.43 & 5.8 & 5.24 & 5.31 & 4.73 & 4.59 & 5.31 & 6.25 & 6.11 & 5.39 & 5.1 & 5.39 \\
\hline 26 & 6.01 & 5.14 & 5.04 & 5.45 & 5.21 & 5.24 & 6.49 & 6.18 & 6.04 & 6.15 & 5.08 & 5.41 \\
\hline 27 & 6.11 & 4.76 & 4.51 & 5.31 & 4.83 & 5.31 & 5.86 & 6.11 & 6.25 & 6.25 & 6.35 & 5.45 \\
\hline 28 & 5.94 & 5 & 4.83 & 5.53 & 4.79 & 6.6 & 6.11 & 6.21 & 6.11 & 5.14 & 5.94 & 5.21 \\
\hline 29 & 5.73 & 5.55 & 4.59 & 5.24 & 5.49 & 6.84 & 5.63 & 6.01 & 6.88 & 5.98 & 5.45 & 5.49 \\
\hline 30 & 5.49 & & 4.59 & 5.04 & 4.69 & 6.04 & 5.49 & 7.4 & 5.39 & 5.49 & 5.55 & 5.84 \\
\hline 31 & 6.25 & & 5 & & 4.9 & & 5.49 & 6.64 & & 6.11 & & 5.7 \\
\hline
\end{tabular}




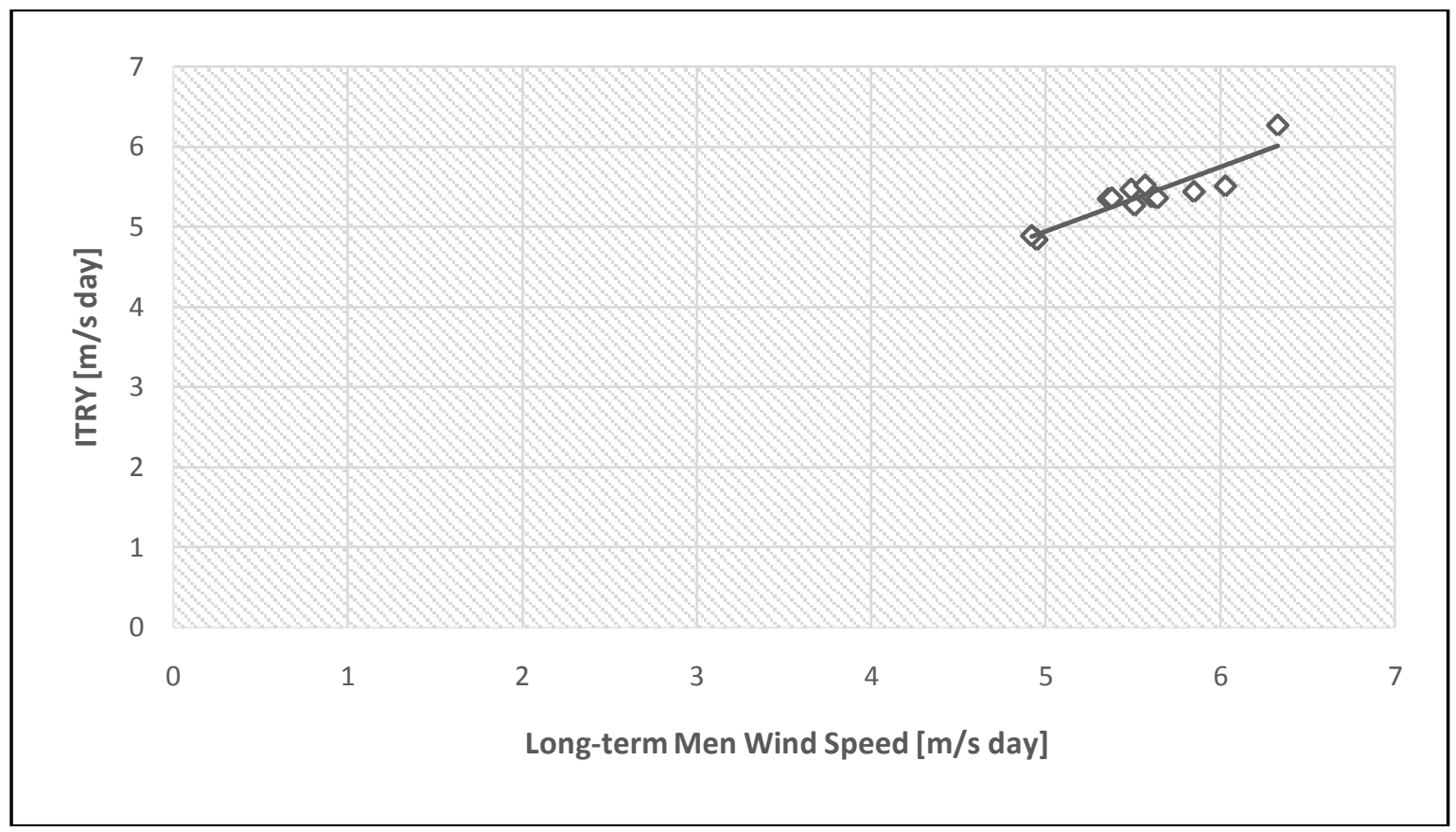

Figure 3 Comparison of monthly averages of the long-term measured wind speed data and TRY data forArmidale NSW, Australia

"Fig. 2" shows the variation of the daily wind speed at 10 meter height from ground level generated from test reference year and all the available long-term measured data for Armidale. Apparently, there is a significant, in the same time, random fluctuation throughout the year daily basis.

"Fig. 3" depicts typical wind speed (ITRY) generated data compared with the long-term measured data set. It shows the differences between ITRY data and the measured data for all the locations considered in this study on a monthly basis for daily global wind speed. As shown in "Fig. 3", there is an agreement on a monthly basis. It is seen that the ITRY data is quite favourable on a monthly basis.

It is worth mentioning that well such TYM study has been developed for Armidale for solar radiation on horizontal surface [15]. So concurrently with this study, hybrid solar and wind energy systems can be designed for Armidale.

\section{CONCLUSION}

Typical wind speed data is very essential for calculations concerning wind energy generation systems and for building energy calculation modelling and analysis. In this study, test reference years for mean daily wind speed for Armidale town NSW, Australia are generated using 20 years of the meteorologically measured data. The daily wind speedat 10 meter height for Armidale is presented throughout the year in a tabular form. Results show that both long-term measured and the typical data are very random throughout the year on daily basis. It is found that there is a clear agreement between the long-term data and typical data on a monthly basis. As well, the results show that Armidale has a high potential of wind energy through most of the year except for the winter months, which is still potential. The generated test reference year would be a useful reference for energy systems designers for any type of building applications.

\section{REFERENCES}

[1] A. Argiriou, S. Lykoudis, S. Kontoyiannidis, C.A. Balaras, D. Asimakopoulos, M. Petrakis, and P.Kassomenos. Comparison of methodologies for TMY generation using 20 years data forAthens, Greece. Solar Energy 66(1), 1999, 33-45.

[2] W. Marion and K. Urban. User's Manual for TMY2s. National Renewable Energy Laboratory, Colorado, USA, 1995.

[3] H. Bulut. Generation of typical solar radiation data for Istanbul, Turkey. International Journal of Energy Research 27(9), 2003, 847-855.

[4] H. Bulut. Typical Solar Radiation Year for South-eastern Anatolia. Renewable Energy 29(9), 2004, $1477-1488$. 
[5] R.L. Fagbenle. Generation of a test reference year for Ibadan, Nigeria. Energy Conversion andManagement 30(1), 1995, 61-63.

[6] J.C. Lam, S.C.M. Hui, and A.L.S. Chan. A statistical approach to the development of a typicalmeteorological year for Hong Kong. Architectural Science Review 39(4), 1996, 201-209.

[7] A. Miguel, and J. Bilbao. Test reference year generation from meteorological and simulatedsolar radiation data. Solar Energy 78(6), 2005, 695-703.

[8] M. Petrakis, H.D. Kambezidis, S. Lykoudis, A.D. Adamopoulos, P. Kassomenos, I.M. Michaelides, S.A. Kalogirou, G. Roditis, I. Chrysis, and A. Hadjigianni. Generation of a typical meteorological year for Nicosia, Cyprus. Renewable Energy 13(3), 1998, 381-388.

[9] S.A.M. Said and H.M. Kadry. Generation of representative weather-year data for SaudiArabia. Applied Energy 48(2), 1994, 131-136.

[10] M.A.M. Shaltout and M.T.Y. Tadros. Typical solar radiation year for Egypt. Renewable Energy 4(4), 1994, 387-393.

[11] J.M. Finkelstein and R.E. Schafer. Improved goodness of fit tests. Biometrika 58(3), 1971, $641-645$.

[12] G. Kalogirou, I. Roditis,, II. Chrysis, and A. Hadjigianni. Generation of a typical meteorological year for Nicosia, Cyprus. Renewable Energy: 13(3), 1998, 381-388.

[13] L. Q. Liu and Z. X. Wang. The development and application practice of wind-solar energy hybrid generation systems in China.Renewable and Sustainable Energy Review 13(6-7), 2009, 1504-1512.

[14] T.N Anderson, M. Duke and J.K. Carson. Generationof a typical meteorological year for Harcourt zone. Journal of Engineering Science and Technology 6(2), 2011, 204-2014

[15] Y. Maklad. Generation of an Annual Typical Meteorological Solar Radiation for Armidale NSW, Australia. IOSR Journal of Engineering (IOSRJEN) 4(4), 2014, 41-45. 